Article

\title{
Genotyping of Infectious Laryngotracheitis Virus (ILTV) Isolates from Western Canadian Provinces of Alberta and British Columbia Based on Partial Open Reading Frame (ORF) a and $b$
}

\author{
Catalina Barboza-Solis ${ }^{1}$, Ana Perez Contreras ${ }^{1}$, Victor A. Palomino-Tapia ${ }^{1}$, Tomy Joseph ${ }^{2} \mathbb{}$, \\ Robin King ${ }^{3}$, Madhu Ravi ${ }^{4}$, Delores Peters ${ }^{4}$, Kevin Fonseca ${ }^{5}$, Carl A. Gagnon ${ }^{6}$ (D), \\ Frank van der Meer ${ }^{1}$ and Mohamed Faizal Abdul-Careem ${ }^{1, *}$ \\ 1 Faculty of Veterinary Medicine, University of Calgary, Health Research Innovation Center 2C53, \\ 3330 Hospital Drive NW, Calgary, AB T2N 4N1, Canada; catalina.barboza@ucalgary.ca (C.B.-S.); \\ ana.perezcontreras@ucalgary.ca (A.P.C.); victor.palominotapia@ucalgary.ca (V.A.P.-T.); \\ fjvander@ucalgary.ca (F.v.d.M.) \\ 2 Animal Health Centre, Ministry of Agriculture, Abbotsford, BC V3G 2M3, Canada; tomy.joseph@gov.bc.ca \\ 3 Agri Food Laboratories, Alberta Agriculture and Forestry, Edmonton, AB T6H 4P2, Canada; blking@telus.net \\ 4 Animal Health and Assurance, Alberta Agriculture and Forestry, Edmonton, AB T6H 4P2, Canada; \\ madhu.ravi@gov.ab.ca (M.R.); delores.peters@gov.ab.ca (D.P.) \\ 5 Provincial Laboratory for Public Health, Calgary, AB T2N 4W4, Canada; \\ kevin.fonseca@albertaprecisionlabs.ca \\ 6 Swine and Poultry Infectious Diseases Research Center (CRIPA), Faculté de médecine vétérinaire, \\ Université de Montréal, 3200 Sicotte, Saint-Hyacinthe, QC J2S 2M2, Canada; carl.a.gagnon@umontreal.ca \\ * Correspondence: faizal.abdulcareem@ucalgary.ca; Tel.: +403-220-4462; Fax: +403-210-9740
}

Received: 5 August 2020; Accepted: 9 September 2020; Published: 11 September 2020

Simple Summary: Infectious laryngotracheitis virus is an economically important acute upper respiratory tract disease in chickens. To control the disease, there are two types of vaccines commercially available, the recombinant viral vector and the live attenuated vaccines. The live attenuated vaccines are effective in disease control, but because of their residual virulence, they can replicate, cause disease, and revert to their original virulent form. Strains of the virus can be categorized as vaccine-related or wild type related. Information is scarce on the type of strains that are circulating in Canada. This study aims to discriminate between wild type and vaccine strains associated with infectious laryngotracheitis cases in the provinces of Alberta and British Columbia between the years 2009-2018. To accomplish this objective, the sequencing of two specific partial genes was performed. As a result, 27 samples from Alberta, and 5 samples from British Columbia were successfully sequenced. From the total samples, $\sim 85 \%$ were related to vaccine strains and the rest categorized as wild type. These results reinforce the concern on current practices surrounding vaccination and the need to implement better biosecurity measures.

Abstract: Infectious laryngotracheitis virus (ILTV) causes an acute upper respiratory disease in
chickens called infectious laryngotracheitis (ILT). Live attenuated vaccines are effective in disease
control; however, they have residual virulence, which makes them able to replicate, cause disease
and revert to the original virulent form. Information is scarce on the molecular nature of ILTV that is
linked to ILT in Canada. This study aims to determine whether isolates originating from ILT cases in
Western Canada are a wild type or vaccine origin. Samples submitted for the diagnosis of ILT between
2009-2018 were obtained from Alberta (AB, $n=46$ ) and British Columbia (BC, $n=9$ ). For genotyping,
a Sanger sequencing of open reading frame (ORF) a and b was used. A total of 27 from AB, and 5 from
BC samples yielded a fragment of 1751 base pairs (bp). Three of the BC samples classified as group
IV (CEO vaccine strains) and 2 as group V (CEO revertant). Of the AB samples, 22 samples clustered 
with group V, 3 with group VI (wild type), and 2 with group VII, VIII, and IX (wild type). Overall, 17 non-synonymous single nucleotide polymorphisms (SNPs) were detected. Further studies are underway to ascertain the virulence and transmission potential of these isolates.

Keywords: infectious laryngotracheitis; genotyping; Canada; Sanger sequencing; live attenuated vaccine

\section{Introduction}

The etiological agent responsible for infectious laryngotracheitis (ILT), an acute upper respiratory tract disease in chickens, is the Gallid alphaherpesvirus 1 (infectious laryngotracheitis virus (ILTV)). ILT is most commonly seen in large, high-density production areas where it is horizontally transmitted [1]. Enzootic forms of ILT show high morbidity (90-100\%), and depending on the infecting strain, more variable mortality (5-70\%) can be observed [2]. Even though viremia has not yet been described, in vitro experiments indicated that ILTV can infect macrophages, potentially leading to infection of non-respiratory sites [3]. The incubation period following natural infection ranges from 6 to 12 days [4,5], while experimental intratracheal challenge usually results clinical signs within 2 to 4 days [6]. Lifelong latent infections will be established following the acute phase. This was first described in the trachea [7] and further demonstrated in the recent year [8]. However, the predominant site of latency is the trigeminal ganglia (TG) [9-12].

Pathogenicity may differ between isolates, but typical acute clinical signs are conjunctivitis, nasal discharge, drop in egg production, sinusitis resulting in decreased body weight gain, and predisposition to other respiratory pathogens [13]. In the case of severe infection, inflammation, necrosis, hemorrhage, and ulceration of upper respiratory tract are found on pathology; furthermore, the formation of diphtheritic membranes may obstruct the airways resulting in death from asphyxia [14]. ILT can affect chickens at any age, although most often at four weeks of age, or even younger [15].

ILT is endemic in backyard flocks of Canada [16], and infrequent ILT outbreaks are recorded in commercial poultry operations in many parts of the country [13,17-19], most recently, (2017-2019) an ILT outbreak in the provinces of Ontario and Québec involved commercial chickens [20,21].

There are two types of ILTV vaccines commercially available: A live attenuated and a recombinant viral vector. Live attenuated virus vaccines can be either embryo (chicken embryo origin, $C E O$ ) or tissue culture passaged (tissue culture origin, TCO) and are satisfactory choices in ILT control [22]. On the downside, their ability to replicate and residual virulence can still cause disease [23,24]. Outbreaks of ILT in the United States (US) were traced back to CEO vaccines [24]. In Canada, the TCO and CEO vaccines are licensed and manufactured and distributed by Merck Animal Health (Madison, NJ, USA) and Merial Select Inc. (Gainesville, GA, USA) respectively. On the other hand, recombinant viral vector vaccines are safer. Although they are more expensive and when compared to live attenuated vaccines, studies have shown that they are not as effective as the CEO vaccine in reducing viral shedding [25-27]. Fowl poxvirus (FPV) and herpesvirus of turkeys (HVT) are the two viral vectors utilized in these recombinant vaccines. The FPV has the glycoprotein B and unique long (UL) 32 gene from ILTV (licensed in Canada and manufacture by CEVA Biomune, Lenexa, KS, USA) [28]. The HVT carries the glycoprotein I and D (licensed in Canada and manufactured by Merck Animal Health, Madison, NJ, USA), and a more recent one has the glycoprotein B (licensed in Canada and manufactured by CEVA Biomune, Lenexa, KS, USA) [29]. Although all these vaccines are licensed in Canada, usage varies in the different provinces. For example, in Alberta (AB), recombinant viral vector vaccines and TCO vaccines are recommended by the Ministry of Alberta Agriculture and Forestry since 2009.

There is an array of molecular assays available for the purpose of differentiating wild-type strains from vaccine viruses. One of the most common assays used is the polymerase chain reaction (PCR)-restriction fragment length polymorphism (RFLP) that targets multiple ILTV genome 
regions [30-33]. However, this assay is time-consuming and expensive. Recently partial sequencing (using Sanger sequencing technology), of the gene open reading frame (ORF) a and b [34], which are unique to the Iltovirus genus [35], was developed as a faster alternative. This method enables the differentiation of vaccine and wild type ILTV strains. In this way, strains are classified as either TCO vaccine-related, $\mathrm{CEO}$ vaccine, $\mathrm{CEO}$ revertant, or wild type through six single nucleotide polymorphisms (SNPs). The ability to differentiate circulating wild type and modified live vaccine viruses, is essential for ILT control [36].

Genomic surveillance of the circulating ILTV strains in a geographical area is essential for the development of control measures [37]. The most recent genetic data of ILTV strains in Canada dates back to 2006 [13], and this previous study examined samples from a 2004-2005 outbreak of ILT in the Niagara Peninsula in Southern Ontario. This later study demonstrated that both wild type and CEO vaccine-derived ILTV strains were circulating.

The objective of this study was to characterize ILTV isolates associated with several ILT cases in Western Canada recorded during 2009-2018, to discriminate between wild type and vaccine strains.

\section{Materials and Methods}

\subsection{ILTV Isolates}

Between 2009 and 2018, qPCR positive clinical ILT samples were collected along with their background information from Agri Food Laboratories, Alberta Agriculture and Forestry, AB $(n=46)$ (Table S1) and from Animal Health Center, British Columbia (BC, $n=9)$ (Table S2). The samples obtained from $\mathrm{AB}$ were comprised of tracheas and tracheal swabs in viral transport medium. Samples obtained from $B C$ had been propagated in chicken embryo kidney cells (CEKC) from tracheal swabs. Tracheal swabs samples and cell culture samples were aliquoted and stored at $-80^{\circ} \mathrm{C}$ along with the tissues until further processing.

\subsection{ILTV Propagation}

The samples that were negative in the PCR assay $(n=7)$ for sequencing, were propagated either in chicken embryo liver cells (CELIC) or by inoculation on the chorioallantoic membranes (CAMs) (Table S3). The SPF chicken eggs were obtained from the Canadian Food Inspection Agency (CFIA), Ottawa, ON, Canada.

The use of embryonated eggs for ILTV propagation was approved by the Health Science Animal Care Committee (HSACC) of the University of Calgary, Alberta, Canada (Protocol number: AC19-0013).

\subsection{ILTV Propagation in Chicken Embryo Liver Cell}

The CELIC were prepared using liver tissues harvested from 14-day-old chicken embryos [38]. The maintenance media comprised of Dulbecco's modified Eagle medium (DMEM) containing $10 \%$ fetal bovine serum (FBS, Gibco, Carlsbad, CA, USA), and $100 \mathrm{U} / \mathrm{mL}$ penicillin and $100 \mu \mathrm{g} / \mathrm{mL}$ streptomycin (Gibco, Carlsbad, CA, USA). The cells were incubated at $37^{\circ} \mathrm{C}$ with $5 \% \mathrm{CO} 2$, and at $>80 \%$ confluence, they were infected with $100 \mu \mathrm{L}$ of the ILTV isolates using DMEM containing $2 \%$ calf serum (CS) and $100 \mathrm{U} / \mathrm{mL}$ penicillin and $100 \mu \mathrm{g} / \mathrm{mL}$ streptomycin. The inoculum consisted of trachea homogenized in $1 \mathrm{~mL}$ of phosphate-buffered saline (PBS, Lonza, Walkersville, MD, USA) and $15 \mu \mathrm{L}$ of antibiotic (100 U/mL penicillin and $100 \mu \mathrm{g} / \mathrm{mL}$ streptomycin). At five days following infection or when the cytopathic effect was extensive, the cells were harvested by freezing and thawing for $30 \mathrm{~min}$ three times. The propagated samples were aliquoted and kept at $-80^{\circ} \mathrm{C}$.

PCR that targets the ORF $a$ and $b$ partial sequence (USDA reference genome coordinates $21,703-23,895)$ was used to verify successful virus propagation. Samples that remained negative by PCR after three cell passages, were subsequently propagated in embryonated eggs from the original sample. 


\subsection{CAM Inoculation}

For the propagation of ILTV in embryonated chicken eggs, 10-day-old SPF eggs were used. Briefly, a small hole was drilled in the air cell, and the egg was placed horizontally, then the air was drawn out with a rubber bulb to create a new, artificial, air cell in which the inoculum was placed using a 25-gauge needle [38]. After five days of inoculation, the eggs were placed in a refrigirator for $24 \mathrm{~h}$. The infected CAMs were extracted and thoroughly minced, then homogenized with a mini homogenizer, and aliquots were stored at $-80^{\circ} \mathrm{C}$. After the CAMs extraction, they were observed for the presence of pock lesions, however none were observed.

\subsection{DNA Extraction}

DNA extraction from tracheal tissues $(n=10)$, tracheal swabs $(n=15)$, and cell culture supernatants $(n=7)$ were performed using QIAamp ${ }^{\circledR}$ DNA Mini Kit (Qiagen, Hilden, Germany) based on manufacturer's instructions. Briefly, tracheas were homogenized with a mini homogenizer and aliquoted. The volume utilized for the DNA extraction was $200 \mu \mathrm{L}$. Later, the extracted DNA was quantified with the Nanodrop 1000 spectrophotometer (ThermoScientific, Wilmington DE, USA) with absorbance at $260 \mathrm{~nm}$.

\subsection{PCR and Amplicon Purification}

Two separate PCR reactions were performed targeting two different regions of ORF a and $b$. The first reaction, made with a total volume of $50 \mu \mathrm{L}$, was based on already published protocol with modifications [34]. The reaction included $200 \mathrm{nM}$ of primers ILTVF1_F2 (5' TTTTGTGCTCATCGC TGTTC3') and ILTV 1R_R1 (5'CAGCGTTGTGAATT GCTTGT3') (USDA reference genome coordinates 21,703-23,895) in a reaction containing 2.5 U Taq DNA polymerase (non-high-fidelity enzyme) per reaction, $0.2 \mathrm{mM}$ of $10 \mathrm{mM}$ dNTP mix, 1X of 10X PCR Buffer- $\mathrm{Mg}, 1.5 \mathrm{mM}$ of $50 \mathrm{mM} \mathrm{MgCl} 2$ and $100 \mathrm{ng}$ of DNA template (Invitrogen, Burlington, ON, Canada) and resulted in a $1751 \mathrm{bp}$ amplicon (Figure S1). The thermocycler conditions were: Initial denaturation at $94{ }^{\circ} \mathrm{C}$ for $2 \mathrm{~min}$, followed by 40 cycles of a three-step amplification protocol: Denaturation at $94{ }^{\circ} \mathrm{C}$ for $30 \mathrm{~s}$, annealing at $58^{\circ} \mathrm{C}$ and elongation at $68^{\circ} \mathrm{C}$ for $60 \mathrm{~s}$ each.

However, after sending the samples for sequencing, the laboratory reported that some samples presented secondary structures or loss of signal, making the sequencing incomplete. Thus, a second reaction targeting a $1000 \mathrm{bp}$ amplicon within the first target was performed to fill the gaps in the first obtained sequence (Figure 1). This reaction was similar but with a different set of primers; ILTVF (5' CGAATGCATCCTTAGACGGG $3^{\prime}$ ) and ILTVR (5' AGCTCGAGAAATTGCAGCG ${ }^{\prime}$ ) (USDA reference genome coordinates 22,364-23,364). The primers were designed using the Primer3 web version 4.0.0 with the default settings (https://primer3plus.com/primer3web/primer3web_input.htm). For this second reaction, thermocycler conditions were: Initial denaturation at $94{ }^{\circ} \mathrm{C}$ for $2 \mathrm{~min}$, followed by 40 cycles of a three-step amplification protocol: Denaturation at $94^{\circ} \mathrm{C}$ for $30 \mathrm{~s}$, annealing at $60^{\circ} \mathrm{C}$ and elongation at $68^{\circ} \mathrm{C}$ for $60 \mathrm{~s}$ each. All PCR products were purified using QIAquick ${ }^{\circledR}$ PCR Purification Kit (Qiagen, Hilden, Germany).

After purification, samples were sent for Sanger sequencing at the University of Calgary Core DNA Services (Calgary, AB, Canada). This facility used an Applied Biosystems 3730xl (96 capillary) genetic analyzer. 


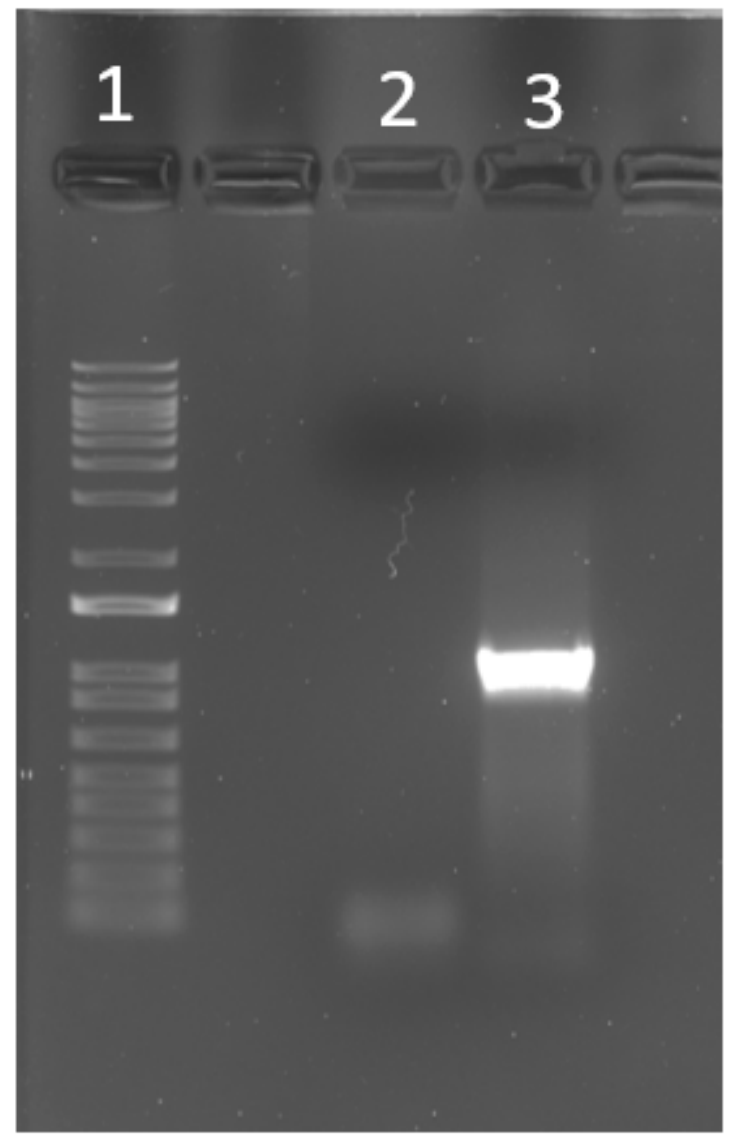

$-1000 \mathrm{bp}$

Figure 1. Visualization of polymerase chain reaction (PCR) product run on a $1 \%$ agarose gel of PCR targeting open reading frame (ORF) a and b (USDA reference genome coordinates 22,364-23,364). The amplicon size is $1000 \mathrm{bp}$. The DNA ladder used was 1 kilo base pairs plus (kb+). Lane 1 is the DNA ladder. The lane labeled 2 is a negative control. Lane labeled as 3 is a known positive sample to an infectious laryngotracheitis virus (ILTV).

\subsection{Phylogenetic Analysis}

Sequences were subjected to the Basic Local Alignment Search tool (BLAST) analysis in NCBI (https://blast.ncbi.nlm.nih.gov/Blast.cgi) to confirm nucleotide identity. A sequence was generated by analyzing the forward and reverse sequences of the first reaction obtained with each sample using the Geneious version 10.0.9 (Biomatters Ltd., Auckland, New Zealand). The sequences obtained from the second PCR reaction were used when a big gap between the reverse and forward sequence of the first reaction was found. The nucleotide sequence of the 32 partial ORF a and $b$ gene segments obtained through this study were aligned with 34 reference ILTV strains downloaded from the GenBank (https://www.ncbi.nlm.nih.gov/genbank/) (Table S4). The alignment was performed using MUltiple Sequence Comparison by Log-Expectation (MUSCLE) on Geneious version 10.0.9 (Biomatters Ltd., Auckland, New Zealand) (Figure 2). To do the analysis, some sequences had to be reduced in size (1599 bp), so that a larger number of samples could be added to the analysis. The reduction was made by ensuring that the critically informative single nucleotide polymorphism (SNPs) necessary for genotyping, mention in the previous study [34], would be included. 


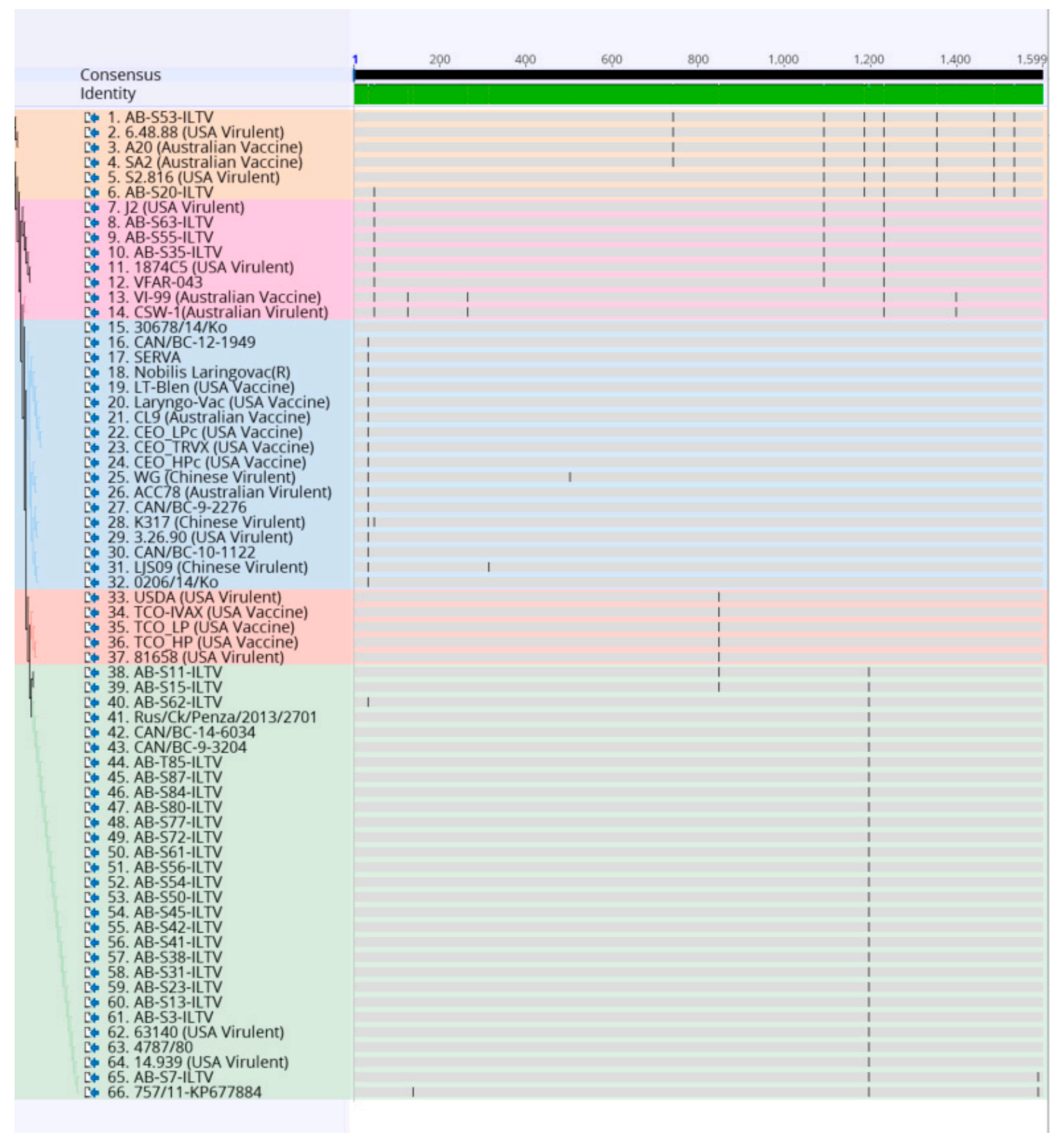

Figure 2. Alignment of the nucleotide sequences of 32 Canadian ILTV strains and 34 ILTV reference strains using MUltiple Sequence Comparison by Log-Expectation (MUSCLE) and Geneious software package. Vertical lines indicate single nucleotide polymorphism (SNP) positions. Samples are color-coded as the phylogenetic tree.

A phylogenetic tree was generated with Phylogenetic inferences using Maximum Likelihood (PHYML) [39] in Geneious set to 1000 bootstrap replicates using the concatenated sequences.

To identify single nucleotide polymorphisms that led to non-synonymous substitutions, all ILTV strains were translated into amino acids and realigned using multiple sequence alignment MUSCLE on the Geneious version 10.0.9 (Biomatters Ltd., Auckland, New Zealand) (Figure 3). 


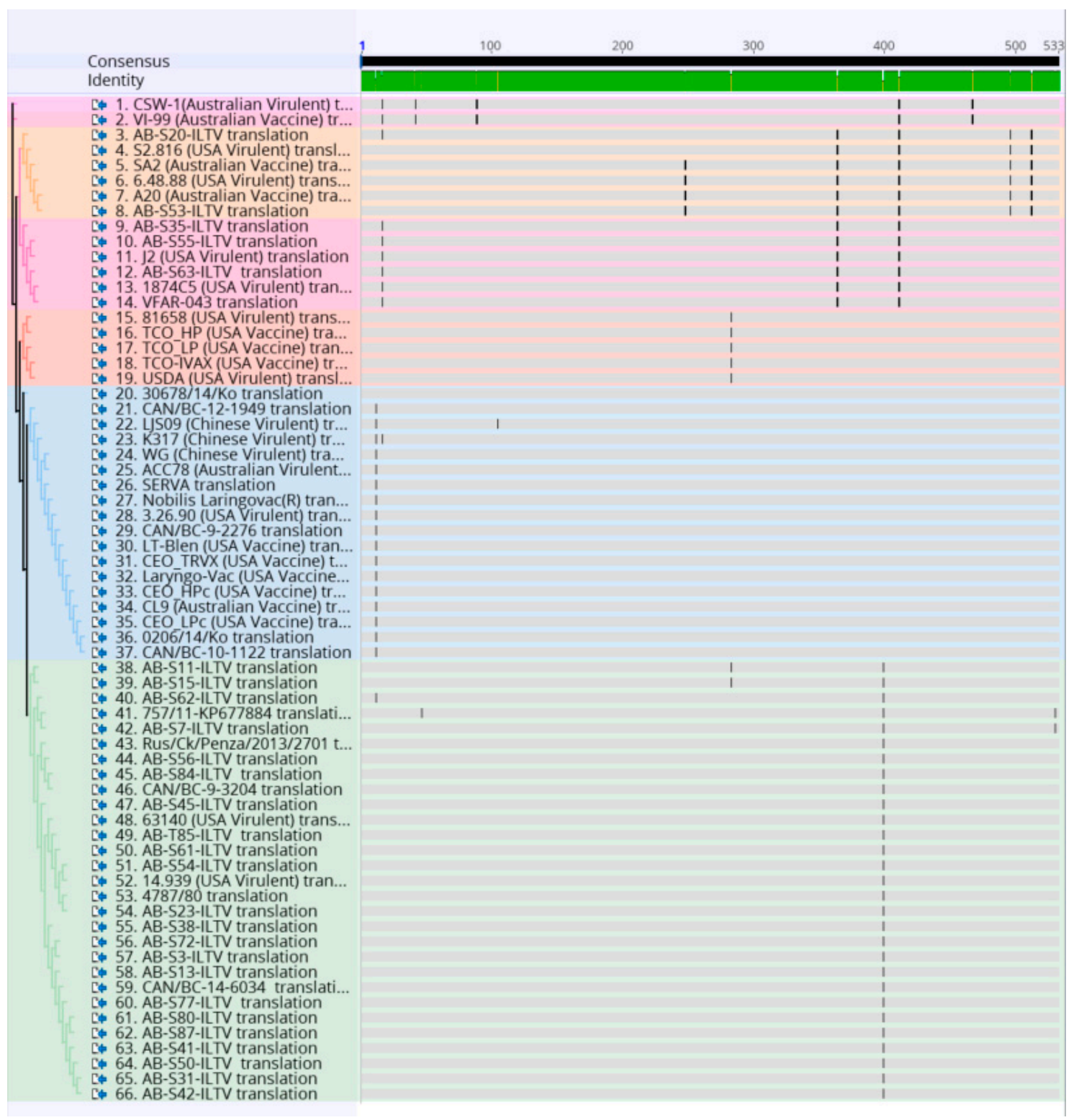

Figure 3. Alignment of the amino acid sequence of 32 Canadian ILTV strains and 36 ILTV reference strains using MUSCLE and Geneious software package. Vertical lines indicate nucleotide change positions. Samples are color-coded as the phylogenetic tree.

The nucleotide sequences were uploaded to the GenBank (accession numbers are in Table 1). 
Table 1. Classification of ILTV isolates from AB and BC is arranged by the year. The table includes the type of flock, province of origin, and the vaccination history. Samples name and genotype have been color-coded as the phylogenetic tree.

\begin{tabular}{|c|c|c|c|c|c|c|}
\hline Isolates & Origin & Year & ORF $a$ and $b$ Gene Genotyping & Province & GenBank Accession Number & Vaccinated \\
\hline CAN/BC-9-2276 & Broiler & 2009 & IV & British Columbia & MT639625 & No \\
\hline CAN/BC-9-3204 & Broiler & 2009 & $\mathrm{~V}$ & British Columbia & MT639621 & Unknown \\
\hline CAN/BC-10-1122 & Layer & 2010 & IV & British Columbia & MT639626 & Yes \\
\hline CAN/BC-12-1949 & Broiler & 2012 & IV & British Columbia & MT639627 & No \\
\hline AB-S3-ILTV & Backyard chicken & 2013 & $\mathrm{~V}$ & Alberta & MT639620 & No \\
\hline CAN/BC-14-6034 & Layer & 2014 & $\mathrm{~V}$ & British Columbia & MT639619 & Unknown \\
\hline AB-S7-ILTV & Backyard chicken & 2014 & $\mathrm{~V}$ & Alberta & MT639603 & No \\
\hline AB-S11-ILTV & Backyard chicken & 2014 & $\mathrm{~V}$ & Alberta & MT639601 & No \\
\hline AB-S13-ILTV & Backyard chicken & 2014 & $\mathrm{~V}$ & Alberta & MT639605 & No \\
\hline AB-S15-ILTV & Backyard chicken & 2014 & $\mathrm{~V}$ & Alberta & MT639602 & Yes \\
\hline AB-S20-ILTV & Backyard chicken & 2015 & VII, VIII, IX & Alberta & MT639631 & No \\
\hline AB-S23-ILTV & Backyard chicken & 2015 & V & Alberta & MT639606 & No \\
\hline AB-S31-ILTV & Backyard chicken & 2015 & $\mathrm{~V}$ & Alberta & MT639607 & No \\
\hline AB-S35-ILTV & Backyard chicken & 2015 & VI & Alberta & MT639628 & No \\
\hline AB-S38-ILTV & Backyard chicken & 2015 & $\mathrm{~V}$ & Alberta & MT639608 & No \\
\hline AB-S41-ILTV & Backyard chicken & 2016 & $\mathrm{~V}$ & Alberta & MT639609 & No \\
\hline AB-S42-ILTV & Backyard chicken & 2016 & $\mathrm{~V}$ & Alberta & MT639610 & No \\
\hline AB-S45-ILTV & Backyard chicken & 2016 & V & Alberta & MT639611 & No \\
\hline AB-S50-ILTV & Backyard chicken & 2016 & V & Alberta & MT639613 & No \\
\hline AB-S53-ILTV & Backyard chicken & 2016 & VII, VIII, IX & Alberta & MT639632 & No \\
\hline AB-S54-ILTV & Backyard chicken & 2016 & V & Alberta & MT639622 & No \\
\hline AB-S55-ILTV & Backyard chicken & 2016 & VI & Alberta & MT639629 & No \\
\hline AB-S56-ILTV & Backyard chicken & 2017 & $\mathrm{~V}$ & Alberta & MT639604 & No \\
\hline AB-S61-ILTV & Backyard chicken & 2017 & $\mathrm{~V}$ & Alberta & MT639623 & No \\
\hline AB-S62-ILTV & Backyard chicken & 2017 & $\mathrm{~V}$ & Alberta & MT639624 & No \\
\hline AB-S63-ILTV & Backyard chicken & 2017 & VI & Alberta & MT639630 & No \\
\hline AB-S72-ILTV & Backyard chicken & 2017 & $\mathrm{~V}$ & Alberta & MT639615 & No \\
\hline AB-S77-ILTV & Backyard chicken & 2017 & $\mathrm{~V}$ & Alberta & MT639616 & No \\
\hline AB-S80-ILTV & Backyard chicken & 2017 & V & Alberta & MT639617 & No \\
\hline AB-S84-ILTV & Backyard chicken & 2017 & $\mathrm{~V}$ & Alberta & MT639618 & No \\
\hline AB-S85-ILTV & Backyard chicken & 2018 & $\mathrm{~V}$ & Alberta & MT639612 & No \\
\hline AB-S87-ILTV & Backyard chicken & 2018 & $\mathrm{~V}$ & Alberta & MT639614 & No \\
\hline
\end{tabular}




\section{Results}

The background information relevant to the analyzed ILT samples is depicted in Table 1. The BC samples originated from commercial broiler and layer flocks, the only sample CAN/BC-10-1122, was accompanied with a vaccination history. All the AB samples originated from chickens from non-commercial farms (in AB, less than 2000 broilers and 300 layers per household/per year are allowed to raise without quota, and defined as non-commercial poultry flocks), only sample AB-S15-ILTV came from a vaccinated flock. Samples obtained from AB came from birds with different ages (1.5 to 24 months), as well as samples obtained from BC (36 days to 12 weeks).

Conventional PCR assays conducted targeting two areas of ORF a and $b$, and the resulting products that were sequenced are shown in Figure 1 and Supplementary Figure S1.

From the initial 55 samples, only 32 were successfully sequenced. The other 23 were either negative in the PCR for sequencing, or the results after the sequencing were of poor quality. Of the 32 PCR positive samples, 27 were from AB, and 5 were from BC (Table 1).

The resulted nucleotide sequences of the 32 ORF $a$ and $b$ gene segments were aligned with 34 reference ILTV strains and illustrated in Figure 2. Further analysis of amino acid sequences of current ORF a and b segments and reference amino acid sequences are shown in Figure 3. Overall, 17 single nucleotide polymorphisms (SNPs) that lead to non-synonymous substitutions were found in the processed samples and references (Table 2).

These ILTV strains could be grouped into four previously published clusters [34], as shown in Figure 4. Of the BC ILTV strains, three were classified in group IV (CEO vaccine), and the remaining two in group $\mathrm{V}$ (CEO revertant). Of the AB isolates, 22 clustered in group V, 3 in cluster VI (wild type), and 2 in cluster VII, VIII, and IX (wild type) (Figure 4).

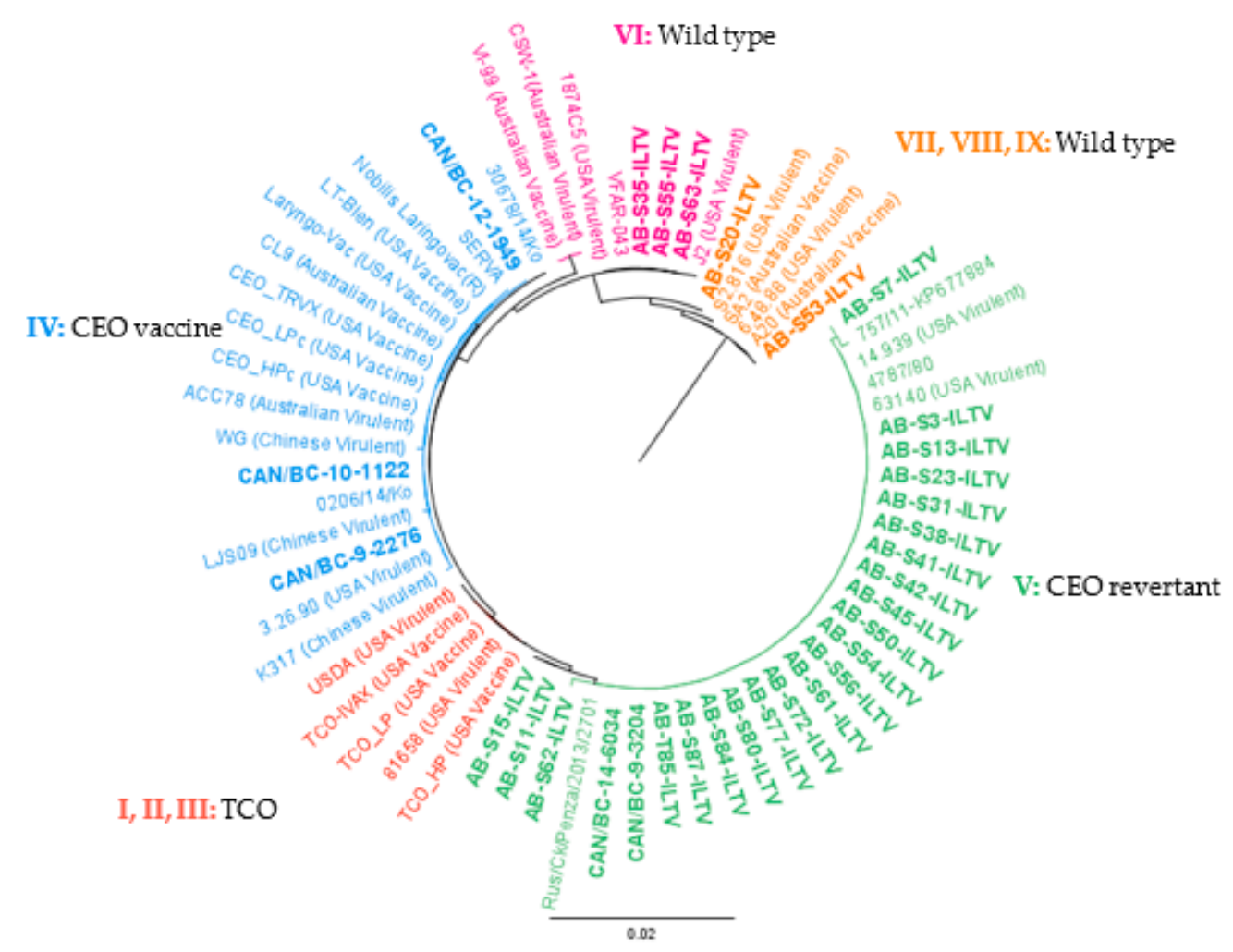

Figure 4. PHYML phylogenetic tree with nucleotide sequences of 66 partial ORF a and b of ILTV. The cladogram includes 34 ILTV reference strains downloaded from the GenBank and 32 ILTV Canadian strains characterized in the current study in bold $(\mathrm{AB}=27, \mathrm{BC}=5)$. The genotype nomenclature used is based on [34]. Geneious version 10.0 was created by Biomatters. Available from http://www.geneious.com. 
Table 2. Single nucleotide polymorphisms and amino acid change in reference strains and processed samples compared to LT-Blen (CEO genotype) as reference. Changes are recorded as shared with all samples that are classified into a specific genotype or as being present in specific strains.

\begin{tabular}{|c|c|c|c|c|c|c|c|}
\hline $\begin{array}{c}\text { SNP } \\
\text { Position }\end{array}$ & $\begin{array}{c}\text { Reference } \\
\text { Nucleotide }\end{array}$ & $\begin{array}{l}\text { Nucleotide } \\
\text { Change }\end{array}$ & $\begin{array}{c}\text { Type of Nucleotide } \\
\text { Change }\end{array}$ & AA Change & Reference AA & AA Change & Genotype and/or Isolates with Same Change \\
\hline 34 & A & C & $\operatorname{Tn} * *$ & 12 & Lys & Gln & All except IV \\
\hline 49 & G & A & $\operatorname{Tr} * * *$ & 17 & Ala & Thr & K317 \\
\hline 50 & $C^{*}$ & $\mathrm{~T}$ & $\operatorname{Tr}$ & 17 & Ala & Val & VI \\
\hline 126 & $\mathrm{~T}$ & A & $\mathrm{Tn}$ & 42 & Cys & * & VI-99 and CSW-1 \\
\hline 139 & $\mathrm{C}$ & $\mathrm{T}$ & $\operatorname{Tr}$ & 47 & Pro & Ser & $757 / 11$ \\
\hline 265 & G & A & $\operatorname{Tr}$ & 89 & Val & Met & VI-99 and CSW-1 \\
\hline 314 & $\mathrm{~T}$ & $\mathrm{C}$ & $\operatorname{Tr}$ & 105 & Leu & Ser & LJS09 \\
\hline 742 & A & G & $\operatorname{Tr}$ & 248 & Thr & Ala & VII, VIII, IX except AB-S20-ILTV and S2.816 \\
\hline 848 & $\mathrm{~T}$ & C & $\operatorname{Tr}$ & 283 & Val & Ala & I, II, III, and AB-S11-ILTV and AB-S15-ILTV \\
\hline 1091 & $\mathrm{~T}$ & $\mathrm{C}$ & $\operatorname{Tr}$ & 364 & Val & Ala & VI, VII, VIII, IX \\
\hline 1196 & A & $\mathrm{C}$ & Tn & 399 & Gln & Pro & V \\
\hline 1231 & G & $\mathbf{T}$ & Tn & 411 & Gly & Cys & VI, VII, VIII, IX \\
\hline 1399 & G & A & $\operatorname{Tr}$ & 467 & Glu & Lys & VI-99 and CSW-1 \\
\hline 1487 & A & G & $\operatorname{Tr}$ & 496 & Lys & Arg & VII, VIII, IX \\
\hline 1533 & AG & GA & $\operatorname{Tr}$ & 512 & Ala & Thr & VII, VIII, IX \\
\hline 1588 & $\mathrm{~T}$ & $\mathrm{C}$ & $\operatorname{Tr}$ & 530 & Trp & Arg & AB-S7-ILTV and 757/11 \\
\hline
\end{tabular}

${ }^{*}$ Nucleotide changes in bold—same as already published findings [34]. ${ }^{* *} \mathrm{Tn}$-transversion. ${ }^{* * *} \mathrm{Tr}-$ transition. 
Of the totality of the processed samples, none clustered in group I, II, and III (TCO related). Of the samples from $\mathrm{AB}$, none clustered in group IV, whereas three of the $\mathrm{BC}$ samples did. The nucleotide identity of ILTV isolates classified in group IV varied from $99.9 \%$ to $100 \%$. The BC samples showed the lowest nucleotide identity (99.9\%) to the rest of the strains in the group.

The ILTV clustering in group V were $99.8-100 \%$ similar. The Italian strain 757/11 was the most distant of the ILTV in group V; however, AB-S7-ILTV showed a 99.9\% identity to the Italian strain 757/11. Samples AB-S11-ILTV and AB-S15-ILTV were genetically identical and were 99.9\% similar to the rest of the strains in group $\mathrm{V}$. It should be noted that both samples were from the same year and could be the same ILTV strain, however, analysis of more variable genome regions are necessary for confirmation. In group VI, all the sequences obtained were identical except for the Australian strains (99.8\%). In the final clusters (VII, VIII, and IX), AB-S53-ILTV was identical to Australian vaccine strains and US virulent strain 6.48.88. In the case of sample AB-S20-ILTV, it was more similar to the US virulent strain $\mathrm{S} 2.816(99.9 \%)$.

\section{Discussion}

The aim of the current study was to characterize the ILTV isolates that originated from various ILT outbreaks in chickens raised in Western Canada. The molecular epidemiology of recent outbreaks of ILTV in chickens from Western Canada is poorly defined. The current study genetically characterized parts of the ORF a and b genes of 32 ILTV isolates collected during ILT outbreaks in Western Canada. It evaluated mostly non-vaccinated flocks, on which the predominant reason for outbreaks were strains related to $\mathrm{CEO}$ vaccine strains. These results contribute to the ongoing discussion related to the safety of using the CEO vaccine and the use of safer options like the recombinant viral vector vaccines. Additionally, these findings support the need to implement better biosecurity measures and effective vaccination strategies in backyard flocks.

ILT outbreaks, related to TCO vaccine strains, are globally reported, but not as frequent as CEO related ones [24,40-42]. In our study, none of the examined AB and BC ILTV isolates were identify as TCO vaccine strains. This is an interesting finding since TCO vaccines are recommended by the Ministry of Alberta Agriculture and Forestry and used by flock owners since 2009. Our findings are in agreement with previous studies that recorded lower transmissibility of TCO vaccine strains compared to CEO vaccines $[30,40,43]$. It has also been shown that TCO vaccines do not revert to virulence like CEO vaccines following the passage for 20 times in vivo [44]. However, this could be due to low pathogenicity or low transmission of TCO vaccine strains into non-commercial poultry, there is evidence that shows that TCO vaccine strains acted as parental strains contributing to the emergence of recombinant strains with higher virulence [41]. To be able to determine if the currently studied ILTV strains are the product of recombination, full genome sequence or sequencing of a bigger genomic region is needed.

On the other hand, CEO related strains are identified in recent outbreaks of ILT in the US [25], and in Ontario, Canada [13]. In the current study, CEO vaccine ILTV strains were identified in samples from BC but not from AB, possibly because the Ministry of Alberta Agriculture and Forestry recommends the use of TCO and not CEO for backyard poultry producers in the last decade. In addition, Egypt, Korea, and Australia have also reported that some ILTV strains are the result of recombination, with at least one of the parental strains being a CEO vaccine virus [41,45-47]. To ascertain whether ILTV strains circulating in BC are a product of recombination events, full genome sequence analysis is necessary. Although CEO vaccine viruses are attenuated, bird-to-bird passages can enable the reversion to a virulent state, which can cause disease [44]. Most of the AB samples classified as CEO revertant (Group V) even though CEO vaccines were discouraged from being used for decades. Similarly, a recent study in Argentina found circulating strains were CEO revertants, even though the use of CEO vaccines has been prohibited for the last 10 years [42]. The hypothesis was that the CEO vaccine strains may have still been circulating, due to various bird-to-bird passage gaining virulence back [44], leading to ILT outbreaks [42]. In AB, ILTV is endemic in non-commercial flocks, and it is possible that CEO 
vaccines used a decade back are still circulating because ILTV infection is a lifelong infection (with an established carrier state), and multi-age birds are common in backyard flocks, providing a perfect scenario for the ongoing spread of the CEO related ILTV. These poultry flocks could potentially be constant sources of this virus for naïve chickens, since the movement of birds through long distances, particularly the rare breeds for various shows and competitions, is common. An alternative explanation may be the transmission of CEO vaccines or revertant strains from neighboring provinces with heavy use of CEO vaccines, which was demonstrated in Brazil [9]. Studies have shown that the combined usage of live attenuated and recombinant vaccines may produce long term protection against CEO revertant strain 63140 [48]. However, to the best of the knowledge of the authors, short term protection of combination or single vaccines against CEO revertant strains have not been studied.

In $A B$, five of the ILTV isolates were wild type and not related to ILT live attenuated vaccines. It is well established that live attenuated ILT vaccines prevent clinical signs, but do not completely protect birds from wild type ILTV replication $[9,25]$. The ILT outbreaks caused by wild type ILTV strains are reported in different countries, although to a lesser degree than CEO vaccine-related ILT outbreaks $[13,24,49]$. The findings of this study are in agreement with the previous study done in Ontario [13], wild type ILTV caused outbreaks are not uncommon in Canada, but in a lesser degree than vaccine-related ILT. It would be interesting to compare our data to data of more recent outbreaks in commercial flocks in Québec.

Through our analysis, we were able to detect 17 SNPs that were non-synonymous. Previously published data reported six SNPs in positions 50, 848, 1196, 1231, 1533, and 1534 [34] that were critically informative to phylogenetically separate the ILTV groups are also identified in our samples. Additionally, 11 different SNPs were found, from which four were shared by specific groups. One was shared by all viruses of group IV in position 34. Two that were found only in group VII, VIII, and IX, and one that was shared by all wild type viruses in position 742 . The other seven SNPs were unique to different strains not shared within their group (Table 2). At comparing CEO vaccine strains and CEO revertant, they differ in two different mutations. CEO vaccine has a transversion mutation in position 34 (Lys12Gln) that is unique to the genotype; on the other hand, CEO revertant has a transversion mutation in position 1196 (Gln399Pro) that is unique to the cluster. Wild type clusters share two common SNPs in position 1091 (Val364Ala) and 1231 (Gly411Cys). However, cluster VI has a unique SNP in position 50 (Ala12Val), and cluster VII, VIII, IX has three unique SNPs in position 742 (Leu105Ser), 1487 (Lys496Arg), and 1533 (Ala512Thr).

A previous study has found that mutations on 12 different genes (ORF c, ORF e, ORF f, UL23, UL39, UL36, UL26, UL28, UL17, UL27, UL10, and UL8) that are exclusive to a CEO revertant strain (63140) in comparison to CEO vaccines from the US; however, ORF a and b were not included in this study [1]. Additionally, it describes seven non-synonymous substitutions in five genes (ICP4, UL54, UL5, UL38, and UL8) involved in virulence/attenuation phenotypes for the CEO group and three mutations in the UL5 gene for the TCO group.

The ORF $a$ and $b$ are two of the five unique genes in the UL region that characterize the Iltovirus genus from other alpha herpesviruses [35]. These specific genes encode a protein product of 40 kilodaltons $(\mathrm{kDa})$ in the case of ORF a and $34 \mathrm{kDa}$ in the case of ORF b [50]. According to database searches, they seem to have no significant homologies to other viral proteins and appear to not have conserved motifs that may point to function or location within virions [51]. Nonetheless, RNA analysis indicates that they might express during virus infection. It was later found that these genes are dispensable for ILTV replication in tissue culture, but might aid in immune evasion or species specificity [52]. Another study suggested that ORF a and b function for virus replication might be important but redundant [35]. It then would be difficult to ascertain what these specific amino acid changes might do in terms of virulence or immune evasion, as it is still unclear the specific role these genes have. However, if or when, further studies are done to ascertain the functions of these specific genes, these mutations might provide useful information to determine differences between genotypes. 


\section{Conclusions}

In conclusion, the majority ( $>80 \%$ ) of the ILT outbreaks in backyard poultry flocks from AB were found to be related to CEO revertants (22 of 27). Although CEO vaccines have not been used for decades in $\mathrm{AB}$, it is possible that underground transmission of $\mathrm{CEO}$ revertants in unvaccinated chickens had been taking place for decades resulting in these recent ILT outbreaks. On the other hand, we also determined that wild-type outbreaks are not uncommon and can be observed in unvaccinated flocks. Outbreaks in backyard flocks could be a source of transmission to commercial operations; however, additional studies and information is necessary to trace transmission between commercial and non-commercial operations. Moreover, further analysis of the CEO vaccine viruses that are isolated from BC flocks is necessary to determine if these virus strains are the product of recombinant events. More studies are underway to ascertain the virulence and transmission potential of these Canadian ILTV isolates. It is also important to generate molecular epidemiology data relevant to more recent outbreaks of ILT in commercial chickens in Québec.

Supplementary Materials: The following are available online at http://www.mdpi.com/2076-2615/10/9/1634/s1, Figure S1: Visualization of PCR product run in a 1\% agarose gel of PCR targeting ORF a and $b$. The amplicon size is $1751 \mathrm{bp}$ (USDA reference genome coordinates 21,703-23,895). The DNA ladder used was 1 kilo base pairs plus $(\mathrm{kb}+)$. Lane 1 is the DNA ladder. Lane labeled 2 is the negative control. Lane labeled 3 is a known positive sample to ILTV., Table S1: Background information of samples from AB provided by Agri Food Laboratories, Alberta Agriculture and Forestry. Samples are arranged by year of submission and the names are color-coded as the phylogenetic tree. Table S2: Background information of samples from BC provided by Animal Health Center. Samples are arranged by year of submission and the names are color-coded as the phylogenetic tree. Table S3: Samples propagated in cell culture and embryonated eggs and number of passages. Table S4: Reference strains used in phylogenetic study arranged by country of origin.

Author Contributions: Conceptualization, M.F.A.-C., T.J., R.K., M.R., D.P., C.A.G.; Methodology, M.F.A.-C., T.J., R.K., M.R., D.P., F.v.d.M., C.A.G. and K.F.; Software, C.B.-S. and F.v.d.M.; Formal analysis, C.B.-S., A.P.C., V.A.P.-T. and F.v.d.M.; Investigation, C.B.-S., A.P.C. and V.A.P.-T.; Resources, T.J., R.K., M.R., D.P., and M.F.A.-C.; Writing-original draft preparation, C.B.-S.; Writing—review and editing, C.B.-S., T.J., R.K., M.R., D.P., C.A.G., M.F.A.-C., K.F. and F.v.d.M.; Supervision, M.F.A.-C., K.F. and F.v.d.M.; Project administration, M.F.A.-C.; Funding acquisition, M.F.A.-C., T.J., R.K., M.R., D.P., C.A.G. and F.v.d.M. All authors have read and agreed to the published version of the manuscript.

Funding: We acknowledge funding from Alberta Agriculture and Forestry (AAF) and Egg Farmers of Alberta (EFA).

Acknowledgments: We thank the BC Animal Health Center, and Agri Food Laboratories and Animal Health and Assurance of the Alberta Agriculture and Forestry for providing clinical samples for ILTV characterization. We acknowledge M. Sarjoon Abdul-Cader and Upasama De Silva Senapathi of University of Calgary for providing help in processing some of the samples. We would like to acknowledge Mohammad Mostafa Nazari Zanjani of the University of Calgary for his insight in the use of bioinformatic tools.

Conflicts of Interest: The authors declare no conflict of interest.

\section{References}

1. Garcia, M.; Volkening, J.; Riblet, S.; Spatz, S. Genomic sequence analysis of the United States infectious laryngotracheitis vaccine strains chicken embryo origin (CEO) and tissue culture origin (TCO). Virology 2013, 440, 64-74. [CrossRef] [PubMed]

2. Hidalgo, H. Infectious laryngotracheitis: A review. Braz. J. Poult. Sci. 2003, 5, 157-168. [CrossRef]

3. Coppo, M.J.; Hartley, C.A.; Devlin, J.M. Immune responses to infectious laryngotracheitis virus. Dev. Comp. Immunol. 2013, 41, 454-462. [CrossRef] [PubMed]

4. Kernohan, G. Infectious laryngotracheitis in fowls. J. Am. Vet. Med. Assoc. 1931, 78, 196-202.

5. Seddon, H.; Hart, L. The ocurrence of infectious laryngotracheitis in fowla in New South Wales. Aust. Vet. J. 1935, 11, 11-221. [CrossRef]

6. Davison, S.; Smith, G.; Eckroade, R.J. Laryngotracheitis in chickens: The length of the preinfectious and infectious periods. Avian Dis. 1989, 33, 18-23. [CrossRef]

7. Bagust, T.J. Laryngotracheitis (Gallid-1) herpesvirus infection in the chicken 4. latency establishment by wild and vaccine strains of ILT virus. Avian Pathol. 1986, 15, 581-595. [CrossRef] 
8. Thilakarathne, D.S.; Hartley, C.A.; Diaz-Méndez, A.; Coppo, M.J.C.; Devlin, J.M. Development and application of a combined molecular and tissue culture-based approach to detect latent infectious laryngotracheitis virus (ILTV) in chickens. J. Virol. Methods 2020, 277, 113797. [CrossRef]

9. Chacon, J.L.; Nunez, L.F.; Vejarano, M.P.; Parra, S.H.; Astolfi-Ferreira, C.S.; Ferreira, A.J. Persistence and spreading of field and vaccine strains of infectious laryngotracheitis virus (ILTV) in vaccinated and unvaccinated geographic regions, in Brazil. Trop Anim. Health Prod. 2015, 47, 1101-1108. [CrossRef]

10. Han, M.G.; Kim, S.J. Efficacy of live virus vaccines against infectious laryngotracheitis assessed by polymerase chain reaction-restriction fragment length polymorphism. Avian Dis. 2003, 47, 261-271. [CrossRef]

11. Hughes, C.S.; Williams, R.A.; Gaskell, R.M.; Jordan, F.T.; Bradbury, J.M.; Bennett, M.; Jones, R.C. Latency and reactivation of infectious laryngotracheitis vaccine virus. Arch. Virol. 1991, 121, 213-218. [CrossRef] [PubMed]

12. Williams, R.A.; Bennett, M.; Bradbury, J.M.; Gaskell, R.M.; Jones, R.C.; Jordan, F.T.W. Demonstration of sites of latency of infectious laryngotracheitis virus using the polymerase chain reaction. J. Gen. Virol. 1992, 73, 2415-2420. [CrossRef]

13. Ojkic, D.; Swinton, J.; Vallieres, M.; Martin, E.; Shapiro, J.; Sanei, B.; Binnington, B. Characterization of field isolates of infectious laryngotracheitis virus from Ontario. Avian Pathol. 2006, 35, 286-292. [CrossRef] [PubMed]

14. MacLachlan, N.J.; Dubovi, E.J. Chapter 9-Herpesvirales. In Fenner's Veterinary Virology, 4th ed.; MacLachlan, N.J., Dubovi, E.J., Eds.; Academic Press: Boston, MA, USA, 2013; pp. 189-216. [CrossRef]

15. Dufour-Zavala, L. Epizootiology of infectious laryngotracheitis and presentation of an industry control program. Avian Dis. 2008, 52, 1-7. [CrossRef] [PubMed]

16. Sary, K.; Chénier, S.; Gagnon, C.A.; Shivaprasad, H.L.; Sylvestre, D.; Boulianne, M. Esophagitis and Pharyngitis Associated with Avian Infectious Laryngotracheitis in Backyard Chickens: Two Cases. Avian Dis. 2017, 61, 255-260. [CrossRef]

17. Gough, A.W.; Pettit, J.R.; Gagnon, A.; Weber, L.J. An outbreak of infectious laryngotracheitis in commercial poultry flocks in Ontario. Can. J. Comp. Med. 1977, 41, 146-151.

18. Vanderkop, M. Alberta. Infectious laryngotracheitis in a flock of layers. Can. Vet. J. 1990, 31, 780.

19. Vanderkop, M. Alberta. Infectious laryngotracheitis in commercial broiler chickens. Can. Vet. J. 1993, 34, 185.

20. UPDATE: Infectious Laryngotracheitis-ILT—Canada. Available online: https://www.canadianpoultrymag. com/disease-watch-infectious-laryngotracheitis-ilt-canada-30562/ (accessed on 21 April 2020).

21. ILT-Quebec. Available online: https:/www.canadianpoultrymag.com/ilt-quebec-30886/ (accessed on 21 April 2020).

22. Garcia, M.; Spatz, S.; Guy, J.S. Infectious Laryngotracheitis. In Disease of Poultry, 13th ed.; Swayne, D.E., Ed.; Wiley-Blackwell: West Sussex, UK, 2013; pp. 161-174.

23. Shehata, A.A.; Halami, M.Y.; Sultan, H.H.; Abd El-Razik, A.G.; Vahlenkamp, T.W. Chicken embryo origin-like strains are responsible for Infectious laryngotracheitis virus outbreaks in Egyptian cross-bred broiler chickens. Virus Genes 2013, 46, 423-430. [CrossRef]

24. Spatz, S.J.; Volkening, J.D.; Keeler, C.L.; Kutish, G.F.; Riblet, S.M.; Boettger, C.M.; Clark, K.F.; Zsak, L.; Afonso, C.L.; Mundt, E.S.; et al. Comparative full genome analysis of four infectious laryngotracheitis virus (Gallid herpesvirus-1) virulent isolates from the United States. Virus Genes 2012, 44, 273-285. [CrossRef]

25. Garcia, M.; Zavala, G. Commercial Vaccines and Vaccination Strategies Against Infectious Laryngotracheitis: What We Have Learned and Knowledge Gaps That Remain. Avian Dis. 2019, 63, 325-334. [CrossRef]

26. Johnson, D.I.; Vagnozzi, A.; Dorea, F.; Riblet, S.M.; Mundt, A.; Zavala, G.; Garcia, M. Protection Against Infectious Laryngotracheitis by In Ovo Vaccination with Commercially Available Viral Vector Recombinant Vaccines. Avian Dis. 2010, 54, 1251-1259. [CrossRef] [PubMed]

27. Vagnozzi, A.; Zavala, G.; Riblet, S.M.; Mundt, A.; García, M. Protection induced by commercially available live-attenuated and recombinant viral vector vaccines against infectious laryngotracheitis virus in broiler chickens. Avian Pathol. 2012, 41, 21-31. [CrossRef] [PubMed]

28. Davison, S.; Eric, N.G.; Susan, C.; Eckroade, R.J. Evaluation of the Efficacy of a Live Fowlpox-Vectored Infectious Laryngotracheitis/Avian Encephalomyelitis Vaccine against ILT Viral Challenge. Avian Dis. 2006, 50, 50-54. [CrossRef] 
29. Esaki, M.; Godoy, A.; Rosenberger, J.K.; Rosenberger, S.C.; Gardin, Y.; Yasuda, A.; Dorsey, K.M. Protection and Antibody Response Caused by Turkey Herpesvirus Vector Newcastle Disease Vaccine. Avian Dis. 2013, 57, 750-755. [CrossRef]

30. Oldoni, I.; Rodriguez-Avila, A.; Riblet, S.; Garcia, M. Characterization of Infectious Laryngotracheitis Virus (ILTV) Isolates from Commercial Poultry by Polymerase Chain Reaction and Restriction Fragment Length Polymorphism (PCR-RFLP). Avian Dis. 2008, 52, 59-63. [CrossRef]

31. Andreasen, J.R.; Glisson, J.R.; Villegas, P. Differentiation of Vaccine Strains and Georgia Field Isolates of Infectious Laryngotracheitis Virus by Their Restriction Endonuclease Fragment Patterns. Avian Dis. 1990, 34, 646-656. [CrossRef] [PubMed]

32. Guy, J.S.; Barnes, H.J.; Munger, L.L.; Rose, L. Restriction Endonuclease Analysis of Infectious Laryngotracheitis Viruses: Comparison of Modified-Live Vaccine Viruses and North Carolina Field Isolates. Avian Dis. 1989, 33, 316-323. [CrossRef] [PubMed]

33. Keeler, C.L.; Hazel, J.W.; Hastings, J.E.; Rosenberger, J.K. Restriction Endonuclease Analysis of Delmarva Field Isolates of Infectious Laryngotracheitis Virus. Avian Dis. 1993, 37, 418-426. [CrossRef]

34. Spatz, S.J.; Garcia, M.; Riblet, S.; Ross, T.A.; Volkening, J.D.; Taylor, T.L.; Kim, T.; Afonso, C.L. MinION sequencing to genotype US strains of infectious laryngotracheitis virus. Avian Pathol. 2019, 48, 255-269. [CrossRef]

35. Fuchs, W.; Veits, J.; Helferich, D.; Granzow, H.; Teifke, J.P.; Mettenleiter, T.C. Molecular biology of avian infectious laryngotracheitis virus. Vet. Res. 2007, 38, 261-279. [CrossRef] [PubMed]

36. Kirkpatrick, N.C.; Mahmoudian, A.; Colson, C.A.; Devlin, J.M.; Noormohammadi, A.H. Relationship between mortality, clinical signs and tracheal pathology in infectious laryngotracheitis. Avian Pathol. 2006, 35, 449-453. [CrossRef] [PubMed]

37. Choi, E.J.; La, T.M.; Choi, I.S.; Song, C.S.; Park, S.Y.; Lee, J.B.; Lee, S.W. Genotyping of infectious laryngotracheitis virus using allelic variations from multiple genomic regions. Avian Pathol. 2016, 45, 443-449. [CrossRef] [PubMed]

38. Williams, S.M.; Dufour-Zavala, L.; Jackwood, M.W.; Lee, M.D.; Lupiani, B.; Reed, W.M.; Spackman, E.; Woolcock, P.R. A Laboratory Manual for the Isolation, Identification and Charaacterization of Avian Pathognes, 5th ed.; American Association of Avian Pathologists: Athens, GA, USA, 2008.

39. Guindon, S.; Gascuel, O. A simple, fast, and accurate algorithm to estimate large phylogenies by maximum likelihood. Syst. Biol. 2003, 52, 696-704. [CrossRef]

40. Oldoni, I.; García, M. Characterization of infectious laryngotracheitis virus isolates from the US by polymerase chain reaction and restriction fragment length polymorphism of multiple genome regions. Avian Pathol. 2007, 36, 167-176. [CrossRef]

41. Bayoumi, M.; El-Saied, M.; Amer, H.; Bastami, M.; Sakr, E.E.; El-Mahdy, M. Molecular characterization and genetic diversity of the infectious laryngotracheitis virus strains circulating in Egypt during the outbreaks of 2018 and 2019. Arch. Virol. 2020, 165, 661-670. [CrossRef]

42. Craig, M.I.; Rojas, M.F.; van der Ploeg, C.A.; Olivera, V.; Vagnozzi, A.E.; Perez, A.M.; Konig, G.A. Molecular Characterization and Cluster Analysis of Field Isolates of Avian Infectious Laryngotracheitis Virus from Argentina. Front. Vet. Sci. 2017, 4, 212. [CrossRef]

43. Rodriguez-Avila, A.; Oldoni, I.; Riblet, S.; Garcia, M. Evaluation of the protection elicited by direct and indirect exposure to live attenuated infectious laryngotracheitis virus vaccines against a recent challenge strain from the United States. Avian Pathol. 2008, 37, 287-292. [CrossRef]

44. Guy, J.S.; Barnes, H.J.; Smith, L. Increased Virulence of Modified-Live Infectious Laryngotracheitis Vaccine Virus Following Bird-to-Bird Passage. Avian Dis. 1991, 35, 348-355. [CrossRef]

45. Agnew-Crumpton, R.; Vaz, P.K.; Devlin, J.M.; O’Rourke, D.; Blacker-Smith, H.P.; Konsak-Ilievski, B.; Hartley, C.A.; Noormohammadi, A.H. Spread of the newly emerging infectious laryngotracheitis viruses in Australia. Infect. Genet. Evol. 2016, 43, 67-73. [CrossRef]

46. La, T.-M.; Choi, E.-J.; Lee, J.-B.; Park, S.-Y.; Song, C.-S.; Choi, I.-S.; Lee, S.-W. Comparative genome analysis of Korean field strains of infectious laryngotracheitis virus. PLoS ONE 2019, 14, e0211158. [CrossRef]

47. Lee, S.W.; Devlin, J.M.; Markham, J.F.; Noormohammadi, A.H.; Browning, G.F.; Ficorilli, N.P.; Hartley, C.A.; Markham, P.F. Phylogenetic and molecular epidemiological studies reveal evidence of multiple past recombination events between infectious laryngotracheitis viruses. PLoS ONE 2013, 8, e55121. [CrossRef] 
48. Palomino-Tapia, V.A.; Zavala, G.; Cheng, S.; Garcia, M. Long-term protection against a virulent field isolate of infectious laryngotracheitis virus induced by inactivated, recombinant, and modified live virus vaccines in commercial layers. Avian Pathol. 2019, 48, 209-220. [CrossRef] [PubMed]

49. Chacon, J.L.; Ferreira, A.J. Differentiation of field isolates and vaccine strains of infectious laryngotracheitis virus by DNA sequencing. Vaccine 2009, 27, 6731-6738. [CrossRef] [PubMed]

50. Veits, J.; Köllner, B.; Teifke, J.P.; Granzow, H.; Mettenleiter, T.C.; Fuchs, W. Isolation and Characterization of Monoclonal Antibodies against Structural Proteins of Infectious Laryngotracheitis Virus. Avian Dis. 2003, 47, 330-342. [CrossRef]

51. Ziemann, K.; Mettenleiter, T.C.; Fuchs, W. Gene arrangement within the unique long genome region of infectious laryngotracheitis virus is distinct from that of other alphaherpesviruses. J. Virol. 1998, 72, 847-852. [CrossRef]

52. Veits, J.; Mettenleiter, T.C.; Fuchs, W. Five unique open reading frames of infectious laryngotracheitis virus are expressed during infection but are dispensable for virus replication in cell culture. J. Gen. Virol. 2003, 84, 1415-1425. [CrossRef]

(C) 2020 by the authors. Licensee MDPI, Basel, Switzerland. This article is an open access article distributed under the terms and conditions of the Creative Commons Attribution (CC BY) license (http://creativecommons.org/licenses/by/4.0/). 